\title{
Prenatal influences on leptin sensitivity and susceptibility to diet-induced obesity
}

\author{
Stefan O Krechowec ${ }^{1}$, Mark Vickers, Arieh Gertler ${ }^{1}$ \\ and Bernhard $\mathbf{H}$ Breier \\ Liggins Institute, The University of Auckland, Private Bag 92019, Auckland, New Zealand \\ ${ }^{1}$ The Institute of Biochemistry, Food Science, and Nutrition, The Hebrew University of Jerusalem, Rehovot, 76100, Israel \\ (Requests for offprints should be addressed to B H Breier; Email: bh.breier@auckland.ac.nz)
}

\begin{abstract}
Obesity and type 2 diabetes are world wide health issues and their incidence is rapidly increasing. Currently the biological factors responsible for the development of obesity are only partially understood. Recent research has shown that maternal nutrition during pregnancy may have long-term metabolic consequences in offspring. In the present study we investigated interactions between prenatal and postnatal nutrition on leptin sensitivity and obesity development. Wistar rats were time-mated and randomly assigned to either ad-libitum (AD) or to $30 \%$ of ad-libitum (UN) food intake throughout pregnancy. After weaning, female offspring were fed standard chow, a high-fat diet or a calorie restricted diet. Female offspring of UN dams were growth retarded at birth and showed
\end{abstract}

increased susceptibility to diet-induced obesity on a highfat diet. At $142 \pm 5$ days of age, leptin sensitivity was measured as a response to 14 days of leptin treatment $(2.5 \mu \mathrm{g} / \mathrm{g} /$ day, s.c.). In UN offspring fed chow, leptin treatment failed to reduce food intake and weight loss was diminished. This leptin resistance observed in UN offspring was independent of diet-induced obesity and was associated with fasting hyperinsulinemia and hypertriglyceridemia. Our study suggests that prenatal nutrition can shape future susceptibility to obesity through alterations in leptin sensitivity and changes in energy metabolism during adult life.

Journal of Endocrinology (2006) 189, 355-363

\section{Introduction}

Obesity and type-2 diabetes are world wide health issues and their incidence is increasing in epidemic proportions (Rodgers et al. 2002). Recent studies, investigating global trends in the incidence of obesity have highlighted three main features that characterise the current epidemic (Chopra et al. 2002, Monteiro et al. 2004, Popkin \& Gordon-Larsen 2004). First, that the increasing incidence of obesity is a global phenomenon, not confined to the developed countries of the world (Popkin \& GordonLarsen 2004). Secondly, that the rate of increase in the incidence of obesity in developing nations is greater than that seen in developed nations (Popkin \& Gordon-Larsen 2004). And thirdly, that globally there is a shift in the burden of obesity onto the poor (Popkin \& GordonLarsen 2004). While overeating and reduced physical activity are currently recognized as the primary obesogenic environmental stimuli driving the obesity epidemic, the current trends suggest that nutritional transition from famine-subsistence to nutritional abundance-excess, may be an important amplifier of the rates of obesity. Recent research suggests that exposure to adverse environmental influences (e.g. undernutrition) during early-life (e.g. prenatal) development can play a key role in determining future susceptibility to obesogenic environmental stimuli (Hales \& Barker 2001, Martorell et al. 2001, Ozanne 2001, Gluckman \& Hanson 2004, McMillen \& Robinson 2005). Adverse prenatal environmental influences are believed to induce permanent adaptive changes in fetal development that act to promote fetal survival in the short-term, but may act to increase vulnerability to later pathogenic environmental stimuli (Godfrey \& Barker 2000). Subsequently, disease risk may be increased when prenatal adaptations are exposed to postnatal factors such as diet or other lifestyle choices (Hales \& Barker 2001, Gluckman \& Hanson 2004). Developmental changes to metabolic processes and endocrine homeostasis may create a predisposition to a range of metabolic disorders, including diet-induced obesity and type-2 diabetes in adult life (Ozanne 2001, Barker 2004, McMillen \& Robinson 2005).

The etiology of obesity is characterized by an imbalance in the homeostatic regulation of energy intake and energy expenditure. The adipokine leptin has been shown to play a central role in the regulation of energy homeostasis 
(Halaas et al. 1995, Maffei et al. 1995, Klein et al. 1996). Leptin stimulates a negative energy balance by increasing energy expenditure and reducing food intake (Schwartz et al. 1996, Halaas et al. 1997, Lollmann et al. 1997, Shimabukuro et al. 1997). Rodents and humans lacking leptin or functional leptin receptors develop severe obesity and hyperphagia (Pelleymounter et al. 1995, Lee et al. 1996, Montague et al. 1997). However, in most obese conditions, plasma leptin is elevated well above levels that should suppress food intake and reduce body weight, yet fails to do so (Maffei et al. 1995, Heymsfield et al. 1999). The failure of endogenous hyperleptinemia to stimulate body weight loss or reduce weight gain in obese individuals suggests that a state of leptin resistance is linked to the development of obesity.

Our previous work in rats suggests that prenatal exposure to maternal undernutrition leads to changes in the regulation of the insulin-leptin endocrine axes which appear to predispose offspring to diet-induced obesity (Vickers et al. 2000, 2001, 2005). We hypothesize that exposure to prenatal undernutrition results in the development of leptin resistance in adult offspring independent of diet-induced obesity. Furthermore, we speculate that this leptin resistance may be amplified by postnatal high fat nutrition and ameliorated by chronic calorie restriction. The aim of the present study was to characterize the responsiveness of adult rats to leptin treatment, following exposure to prenatal undernutrition and to investigate how prenatal nutrition can interact with different levels of postnatal nutrition, to influence the development of obesity and related metabolic complications.

\section{Materials and Methods}

\section{Materials}

Recombinant rat leptin (r-rat leptin) was prepared by over-expression in Escherichia coli, isolation of inclusion bodies, refolding and purification to homogeneity by ion-exchange and gel filtration chromatography. The biological activity of $\mathrm{r}$-rat leptin was documented in vitro in BAF/3 cells stably transfected with the long form of the human leptin receptor (LEPRb) and found to be equal to r-human leptin (data not shown). In vivo biological activity of different doses of r-rat leptin was evaluated in mature female Wistar rats. Rat leptin was dissolved in sterile water and was given s.c. as a split dose bolus injection $(0800 \mathrm{~h}$ and $1700 \mathrm{~h})$ for 7 days. Animals were divided into five treatment groups receiving either saline or r-rat leptin at a total dose of $0 \cdot 1,0 \cdot 5,1 \cdot 0$ or $5 \cdot 0 \mu \mathrm{g} / \mathrm{g}$ per day. With increasing doses of leptin treatment, body weights changed during the 7 day treatment period from $3.0 \pm 0.9 \mathrm{~g}$ in saline treated animals to $-6.9 \pm 1.9 \mathrm{~g}$, $-8.6 \pm 1.6 \mathrm{~g} \quad(P<0.05), \quad-8.5 \pm 1.9 \mathrm{~g} \quad(P<0.05)$ and $-14 \cdot 8 \pm 1 \cdot 7 \mathrm{~g}(P<0 \cdot 001)$ at leptin doses of $0 \cdot 1,0 \cdot 5,1 \cdot 0$,
$5 \cdot 0 \mu \mathrm{g} / \mathrm{g}$ per day respectively. On the basis of data obtained from this pilot study, a dose of $2 \cdot 5 \mu \mathrm{g} / \mathrm{g}$ per day was chosen for the present study.

\section{Animal Study Design}

Virgin Wistar rats (age $100 \pm 5$ days, $n=30$ per group) were time mated using a rat oestrus cycle monitor to assess the stage of oestrus of the animals before introducing the male. After confirmation of mating, rats were housed individually in standard rat cages containing wood shavings as bedding with free access to water. All rats were kept in the same room with a constant temperature maintained at $25^{\circ} \mathrm{C}$ and a $12 \mathrm{~h}$ light: $12 \mathrm{~h}$ darkness cycle. Pregnant animals were randomly assigned to receive a standard chow diet (No: 2018; Harlan Teklad, UK) either ad libitum (AD-group) or at $30 \%$ of ad libitum intake (UN-group) throughout pregnancy. Food intake and maternal weights were recorded daily until birth. After birth, pups were weighed and litter size recorded. To prevent a carry over of prenatal undernutrition to the immediate neonatal period, pups from undernourished mothers were cross-fostered onto dams that received AD feeding throughout pregnancy. Litter size was adjusted to eight pups for all litters to assure adequate and standardized nutrition until weaning. After weaning, female offspring from the two groups of dams (AD offspring and UN offspring) were divided into three postnatal nutritional groups $(n=16)$ to be fed either: ad libitum on standard chow, ad libitum on a high-fat diet (30\% fat wt/wt) or a calorie restricted diet ( $70 \%$ of ad libitum chow intake) The chow diet provided $3.4 \mathrm{kcal} / \mathrm{g}$ (dry weight) and contained $18.9 \%$ protein, $5.7 \%$ fat, and $57.3 \%$ carbohydrate. The high-fat diet comprised Teklad diet 2018 supplemented with high quality beef fat, butter fat, corn oil, molasses sugar, casein, and Teklad vitamin (40060) and mineral (AIN-36, 170915) mixes. The high-fat diet provided $5 \mathrm{kcal} / \mathrm{g}$ (dry weight) and contained $28.7 \%$ protein, $30 \%$ fat and $31 \cdot 1 \%$ carbohydrate. The protein/energy ratio and vitamin and mineral content in the two diets were identical and in accordance with the requirements for standard rat diets. Body weight and food intake of all offspring were measured daily for the first 8 weeks then on every second day. One week prior to leptin treatment, daily body weight and food intake measurements were resumed and continued for the remainder of the study. At $142 \pm 5$ days of age AD and UN offspring were divided into two further treatment groups ( $n=8$ per group) receiving r-rat leptin $(2.5 \mu \mathrm{g} / \mathrm{g} /$ day $)$ or saline for 14 days by twice daily s.c. injection ( $0800 \mathrm{~h}$ and $1700 \mathrm{~h}$ ). Body weight and food intake were measured daily throughout the treatment period. At the end of treatment, rats were fasted overnight and euthanized, two hours after a final injection of leptin. All animals were euthanized by decapitation under halothane anesthesia. Blood was collected into heparinized vacutainers and stored on ice 
$\left(4^{\circ} \mathrm{C}\right)$ until centrifugation and removal of supernatants for analysis. Body length (nose-anus), retroperitoneal fat pad and carcass weights were recorded. All animal work was approved by the Animal Ethics Committee of the University of Auckland.

\section{Endocrine analyses and blood biochemistry}

Fasting plasma leptin and insulin concentrations were determined by RIA as described previously (Vickers et al. 2000). For rat leptin, the half-maximally effective dose (ED-50) of the assays was $0.33 \mathrm{ng} / \mathrm{ml}$ and the intra- and inter-assay coefficients of variation were both $<10 \%$. For rat insulin, the ED-50 was $0.73 \mathrm{ng} / \mathrm{ml}$ and the intra- and inter-assay coefficients of variation were $8 \%$ and $10 \%$ respectively. Rat plasma c-peptide and total ghrelin were determined by commercially available rat specific RIA kits (No: RCP-21K and GHRT-89HK respectively; Linco, St Charles, MO, USA). For rat c-peptide, the ED-50 was $204.56 \mathrm{pM}$ and the intra- and inter-assay coefficients of variation were $<5 \%$ and $<10 \%$ respectively. For rat ghrelin, the ED-50 was $775 \mathrm{pg} / \mathrm{ml}$ and the intra- and inter-assay coefficients of variation were $<5 \%$ and $<15 \%$ respectively. Plasma free fatty acids and total triglycerides were measured by commercially available diagnostic kits (Roche no. 11383175001 and Sigma no.TR0100 respectively).

\section{Statistical analysis}

Data are presented as means \pm S.E.M. and significance level was set at $P \leq 0 \cdot 05$. Postnatal growth curves and changes in body weight and food intake with leptin treatment were analyzed by repeated measurements of ANOVA, and groups were compared by Fisher's projected least significant difference post hoc analysis. Endocrine, biochemical and pre- treatment food intake measurements were analyzed by three-way factorial ANOVA (prenatal nutrition, postnatal diet and leptin treatment as factors), and groups were compared by Fisher's projected least significant difference post hoc analysis.

\section{Results}

Offspring of undernourished mothers are growth retarded at birth and develop increased susceptibility to diet-induced obesity during postnatal life

Exposure to maternal undernutrition throughout pregnancy caused fetal growth retardation in female UN offspring as reflected by a significant reduction in birth weight (AD $5.9 \pm 0.03 \mathrm{~g}$, UN $4.2 \pm 0.04 \mathrm{~g}, P<0.0001$ ) and body length (AD $48 \cdot 37 \pm 0 \cdot 18 \mathrm{~mm}$, UN $43 \cdot 45 \pm$ $0.19 \mathrm{~mm}, P<0.0001)$. Throughout the neonatal period until weaning, body weight remained significantly

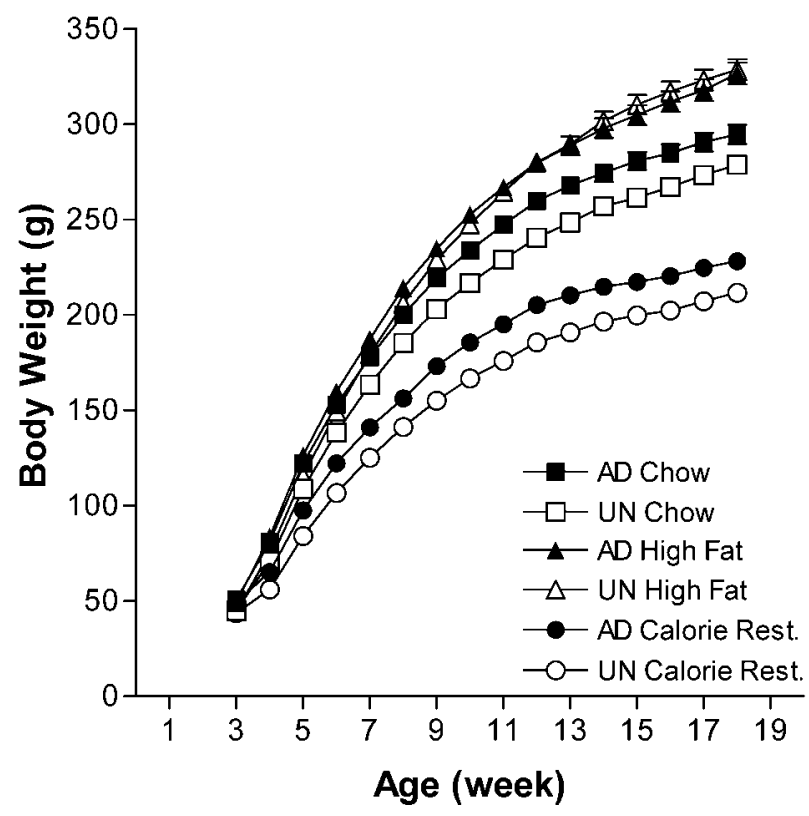

Figure 1 Growth curves of female offspring of $A D$ and $U N$ dams. Effect of prenatal nutrition: $P<0.001$ (AD chow vs UN chow and $\mathrm{AD}$ calorie rest. vs UN calorie rest.); effect of postnatal nutrition: $P<0.001$ (chow vs calorie rest, chow vs high-fat and calorie rest. vs high-fat). Data are mean \pm S.E.M., $n=16$ per group, differences determined by repeated-measures ANOVA.

reduced in UN offspring (body weight at weaning: AD $48.9 \pm 0.5 \mathrm{~g}$, UN $41.9 \pm 0.7 \mathrm{~g}, P<0 \cdot 0001)$. After weaning, UN offspring fed on standard chow or on the calorie restricted diet had postnatal growth trajectories similar to respective $\mathrm{AD}$ offspring, yet remained significantly lighter and shorter (Fig. 1). Calorie restriction after weaning, significantly reduced postnatal weight gain in both $\mathrm{AD}$ and UN offspring (Fig. 1). In contrast, high-fat feeding caused a significant increase in weight gain and adult body weight in both $\mathrm{AD}$ and $\mathrm{UN}$ offspring (Fig. 1). Interestingly, UN offspring on high-fat nutrition showed significant catch-up growth in terms of body weight, but body length remained shorter (Table 1). UN offspring fed a high-fat diet reached the same body weight as AD offspring on chow by 6 weeks of age and achieved the body weight of the AD offspring fed a high-fat diet by 11 weeks of age (Fig. 1).

Retroperitoneal fat mass, calculated as a percentage of carcass weight, was significantly increased in UN offspring $(P<0 \cdot 05$, Table 1$)$ but was normalized by postnatal calorie restriction (Table 1). In both $A D$ and $U N$ offspring retroperitoneal fat mass was increased by high-fat nutrition and decreased by calorie restriction $(P<0 \cdot 001$, Table 1). Calorie intake in offspring was measured prior to leptin treatment (130-140 days). No differences in calorie intake between $\mathrm{AD}$ and $\mathrm{UN}$ offspring were observed at this time point (Table 1). 

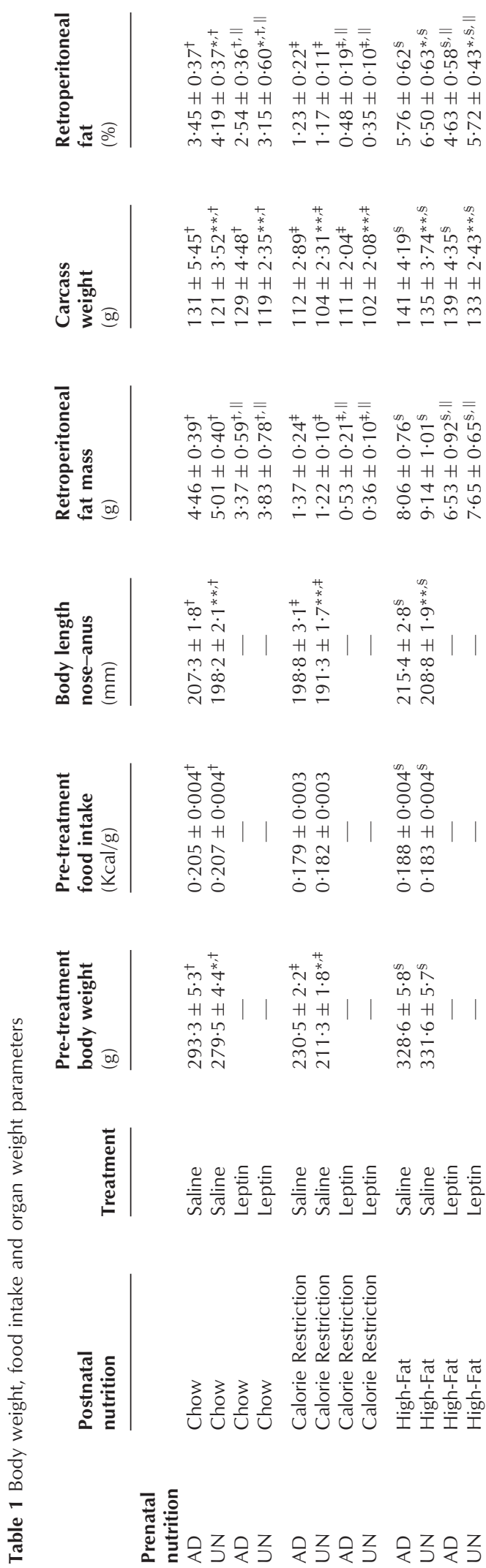

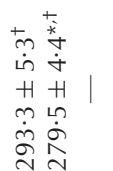

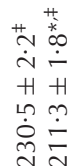

$\stackrel{m}{m} \stackrel{m}{\wedge}$

เ่ เ่

$+\mathrm{H}$

ب

$\stackrel{\dot{m}}{\mathrm{~N}} \stackrel{\dot{m}}{m}$
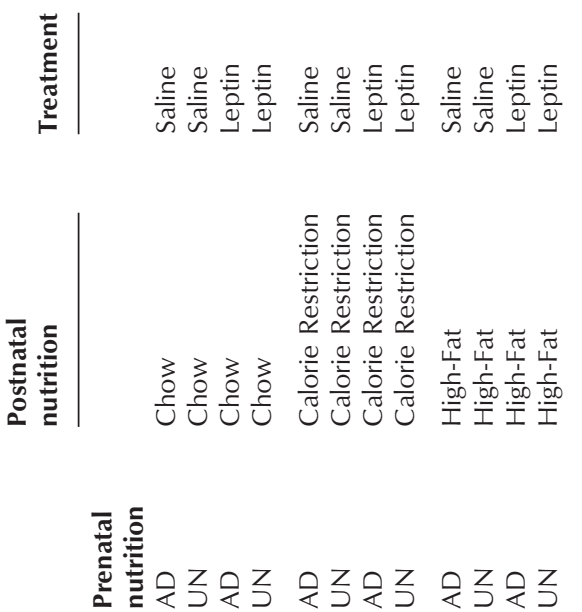

Plasma leptin concentrations were significantly reduced by calorie restriction and significantly increased by high-fat nutrition $(P<0 \cdot 001$ respectively, Table 2$)$ in both $\mathrm{AD}$ and UN offspring. Similarly, fasting plasma insulin levels were significantly reduced $(P<0 \cdot 05$, Table 2$)$ by calorie restriction in both $\mathrm{AD}$ and $\mathrm{UN}$ offspring. While differences in plasma insulin between $\mathrm{AD}$ and UN offspring did not reach significance $(P=0 \cdot 104$, Table 2$)$, plasma C-peptide concentrations were significantly $(P<0 \cdot 05$, Table 2$)$ increased in all UN offspring across the entire experimental setting, suggesting a state of fasting hyperinsulinemia in UN offspring during adult life. In both $\mathrm{AD}$ and UN offspring, fasting C-peptide concentrations were significantly reduced by calorie restriction $(P<0 \cdot 05$, Table 2$)$ and significantly increased by high-fat nutrition $(P<0 \cdot 001$, Table 2$)$. No significant differences in total fasting plasma ghrelin concentrations were observed between $\mathrm{AD}$ and $\mathrm{UN}$ offspring; however there was a trend toward lower plasma ghrelin levels in UN offspring $(P=0.0656)$. In both $\mathrm{AD}$ and $\mathrm{UN}$ offspring, total plasma ghrelin was significantly elevated by calorie restriction and reduced by high-fat nutrition $(P<0 \cdot 001$, Table 2$)$. No significant differences in fasting plasma FFA concentrations were observed between $\mathrm{AD}$ and $\mathrm{UN}$ offspring. In both AD and UN offspring, plasma FFA were significantly elevated by calorie restriction $(P<0 \cdot 001$, Table 2$)$ while high-fat nutrition had no effect. Total plasma triglyceride levels were significantly elevated in UN offspring $(P<0 \cdot 05$, Table 2$)$. Calorie restriction normalized fasting plasma triglyceride concentrations in UN offspring but had no effect in $\mathrm{AD}$ offspring.

\section{Adult offspring of undernourished mothers develop leptin resistance independent of diet-induced obesity}

Leptin sensitivity in adult female offspring was measured as the response of body weight and food intake to 14 days of leptin treatment. Leptin treatment caused significant weight loss $(P<0 \cdot 001$, Fig. 2A) and reduced food intake $(P<0 \cdot 05$, Fig. $2 \mathrm{~B})$ in $\mathrm{AD}$ offspring on chow nutrition. In UN offspring fed chow nutrition, leptin treatment failed to reduce food intake (Fig. 2B), and weight loss after 14 days was significantly less than that of AD chow fed offspring $(P<0 \cdot 05$, Fig. $2 \mathrm{~A})$. In $\mathrm{AD}$ and $\mathrm{UN}$ offspring on high-fat nutrition, leptin treatment was only able to reduce body weight to a small but significant extent (Fig. 2C) and had no significant effect on food intake (Fig. 2D). In AD offspring, high-fat nutrition diminished the ability of exogenous leptin treatment to reduce body weight (Figs 2A \& 2C). However, in UN offspring, high-fat nutrition had no further effect on the ability of leptin treatment to cause weight loss (Figs 2A \& 2C). In offspring on calorie restriction weight loss in response to leptin treatment was delayed until the tenth day of treatment (Fig. 2E). In AD offspring, calorie restriction diminished the ability of leptin treatment to cause weight 

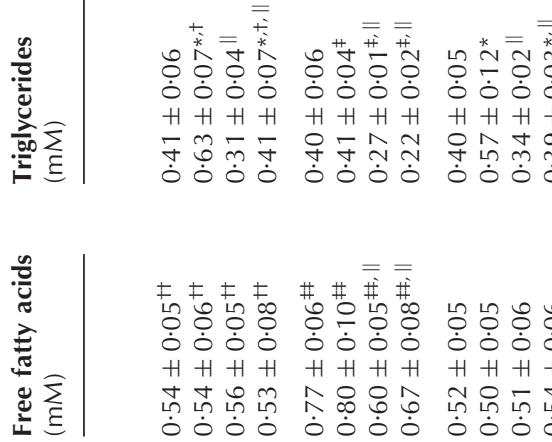

는ำㅇํㅇ

$\dot{0} \dot{0} \dot{0}$

$\mathrm{H}+\mathrm{H} H \mathrm{H}$

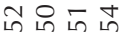

0 ơ
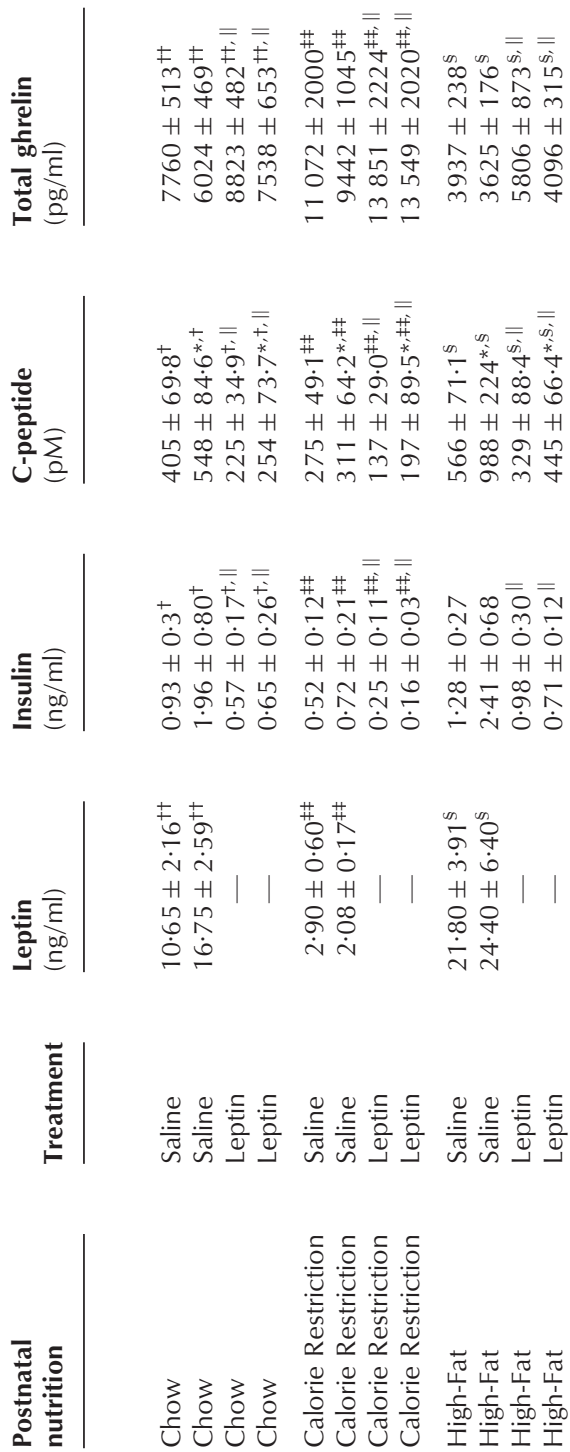$$
\text { . }
$$
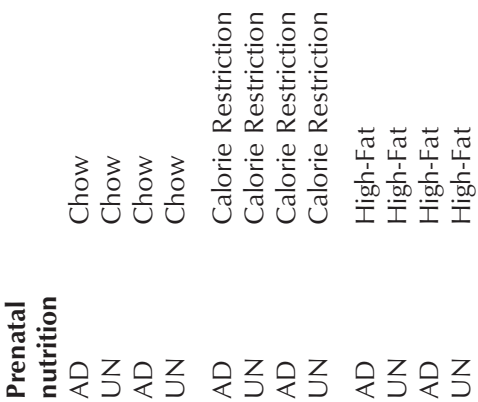

loss (Figs $2 \mathrm{~A} \& 2 \mathrm{E})$. In UN offspring calorie restriction did not influence the ability of leptin treatment to cause weight loss (Figs 2A \& 2E). In both AD and UN offspring on calorie restriction, leptin treatment had no significant effect on food intake (Fig. 2F). Both $A D$ and $U N$ offspring on calorie restriction consumed the entirety of the daily food allotments assigned, irrespective of leptin treatment, this caused food intake to be identical across saline and leptin treated groups (Fig. 2F).

Fourteen days of peripheral leptin treatment caused a significant reduction in retroperitoneal fat mass and fasting plasma insulin, c-peptide and triglyceride levels in all treated offspring (Tables $1 \& 2$ ). There was no difference between $\mathrm{AD}$ and UN offspring or between different diet groups on the effect of leptin treatment on fat mass, insulin, c-peptide and triglyceride concentrations. However, leptin treatment normalized FFA concentrations in both $\mathrm{AD}$ and UN offspring on calorie restriction, but did not have any affects on FFA levels in any other experimental group. Total plasma ghrelin was significantly elevated by leptin treatment in all offspring (Table 2) and there was no effect of diet on plasma ghrelin response to leptin treatment.

\section{Discussion}

Our current results show that female offspring of undernourished mothers (UN offspring), maintained ad libitum on a standard chow diet, are leptin resistant in adulthood. This leptin resistance occurs in the absence of overt obesity and hyperleptinemia, which are commonly seen in rats made leptin resistant through high fat feeding. Interestingly, the magnitude of leptin resistance in chow-fed UN offspring appears to be equivalent to that observed in obese hyperleptinemic AD offspring fed a high-fat diet. However, in the absence of obesity and hyperleptinemia, leptin resistance in chow-fed UN offspring is associated with markers of fasting hyperinsulinemia and hypertriglyceridemia. These findings suggest that changes in endocrine and metabolic function, brought about by exposure to prenatal undernutrition, leads to the development of leptin resistance in adulthood, independently of diet-induced obesity.

Recent research in rats and mice exposed to dietinduced obesity suggests that leptin resistance may play a causal role in the development of obesity (Frederich et al. 1995, El-Haschimi et al. 2000, Lin S et al. 2000, Lin L et al. 2001). Our present study shows that whilst chow-fed UN offspring appear to be insensitive to leptin, they remain small, show no signs of catch-up growth or obesity, and only demonstrate a modest increase in abdominal adiposity. However, when UN offspring are placed on a high-fat diet we observe accelerated weight gain, catch-up growth and the rapid development of overt obesity. These results support earlier findings which have 

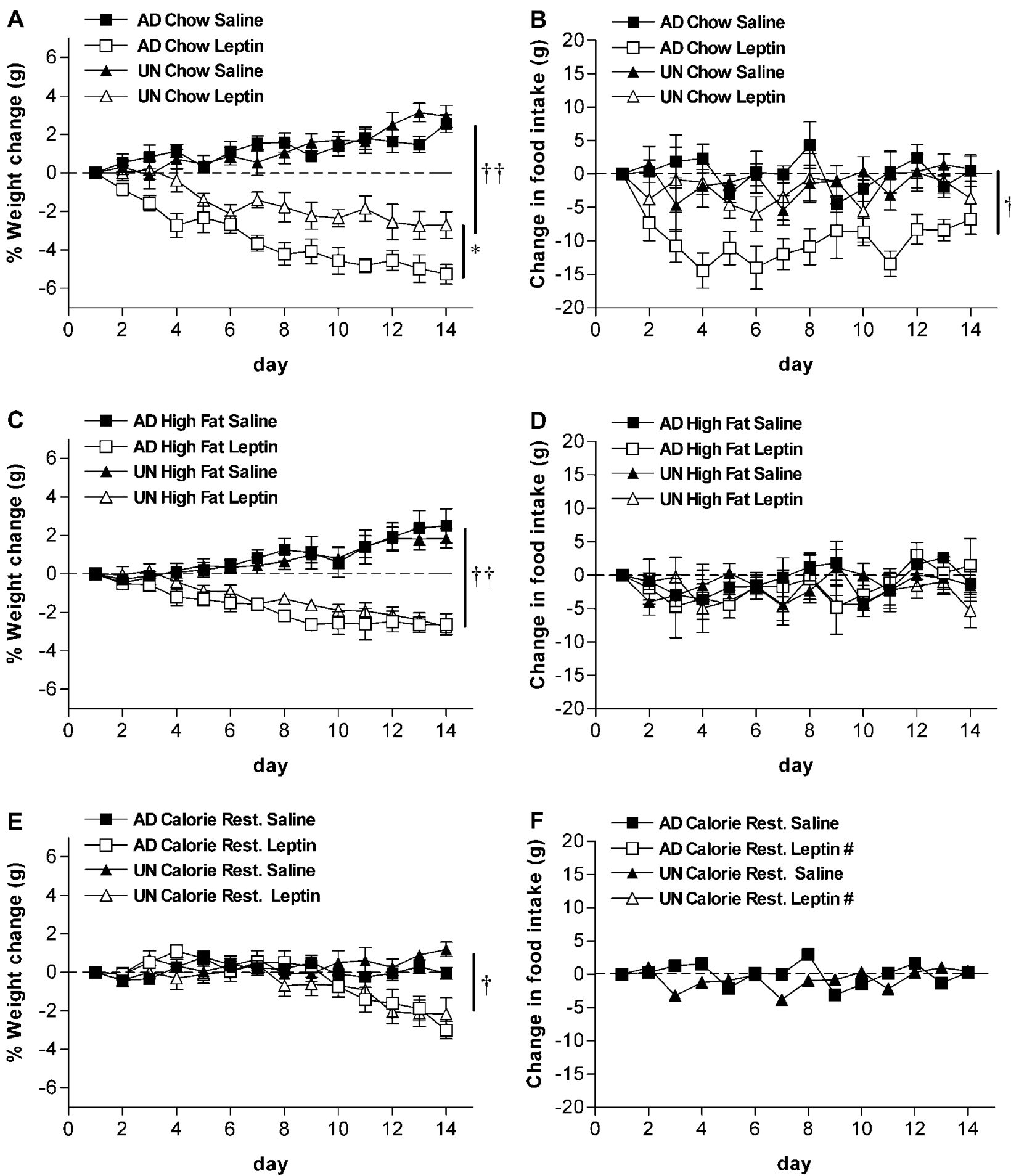

Figure 2 Response to leptin treatment in female offspring of AD and UN dams. (A) Change in body weight in chow-fed offspring ( ${ }^{*} P<0 \cdot 05$, AD chow leptin vs UN chow leptin, $\dagger+P<0 \cdot 001$, saline vs leptin). (B) Change in food intake in chow-fed offspring ( $P<<0 \cdot 05$, $A D$ chow saline vs AD chow leptin). (C) Change in body weight in high-fat fed offspring ( $\dagger+P<0 \cdot 001$, saline vs leptin). (D) Change in food intake in high-fat fed offspring. (E) Change in body weight in calorie restricted offspring ( $P<0 \cdot 05$, saline vs leptin). (F) Change in food intake in calorie restricted offspring. \# Change in food intake in leptin treated offspring on calorie restriction was identical to saline treated offspring. Data are mean \pm S.E.M., $n=8$ per group, differences determined by repeated-measures ANOVA. 
shown that the offspring of undernourished mothers have elevated weight gain trajectories on high-fat nutrition and an enhanced susceptibility to diet-induced obesity (Vickers et al. 2000, 2001, 2002). Predictably, when UN offspring are kept on a calorie restricted diet they remain small and lean, and show no evidence of increased adiposity. These findings suggest that while exposure to prenatal undernutrition can reduce leptin sensitivity in adulthood the progression to overt obesity requires a critical interaction with postnatal obesogenic dietary factors. Rather than playing a direct role in the development of obesity, leptin resistance in UN offspring appears to increase susceptibility to postnatal obesogenic dietary factors, providing a mechanism for the accelerated deposition of body fat when an obesogenic environment is encountered. In the absence of obesogenic environmental influences leptin resistance in UN offspring does not lead to the development of overt obesity.

The mechanisms proposed to underlie the development of leptin resistance in models of diet-induced obesity focus on defects influencing leptin transport across the blood brain barrier $(\mathrm{BBB})$ and signaling downstream of the leptin receptor (El-Haschimi et al. 2000, Levin et al. 2004). Current theories further speculate that dietinduced leptin resistance may be mediated through bloodborne circulating factors associated with high-fat feeding (Heshka \& Jones 2001, Lin L et al. 2001, Harris et al. 2003, Munzberg et al. 2004). Recent work by Banks et al. (2004) has demonstrated that elevations in plasma triglycerides can have a direct effect on the $\mathrm{BBB}$, rapidly impairing leptin transport into the brain. In our current study, leptin resistance is observed in conjunction with elevations in fasting plasma triglycerides and hyperinsulinemia in UN offspring fed chow and high fat nutrition. Recent work by Zammit et al. (1999) and Zammit (2002) have demonstrated that repeated exposure of the liver to elevated levels of insulin has a potent stimulatory effect on hepatic triglyceride production. Our findings of concomitant hyperinsulinemia and fasting hypertriglyceridemia suggest that over-stimulation of hepatic triglyceride production through insulin action may form a mechanistic basis for the development of leptin resistance in UN offspring that is independent of high fat nutrition and obesity. Concurrently, hyperinsulinemia may also influence leptin sensitivity through cross-talk between the insulin and leptin receptors (Brabant et al. 2005). However, when UN offspring are maintained on calorie restriction, increases in adiposity and elevations in plasma triglycerides are normalized, but c-peptide levels remain elevated. On this basis, we can speculate that interventions aimed at reducing plasma insulin levels or hypertriglyceridemia may act to ameliorate leptin resistance and decrease susceptibility to diet-induced obesity. Studies are currently underway in our laboratory that explores this hypothesis.

While a high-fat diet is well known to induce leptin resistance, studies with calorie restriction suggest that short-term calorie restriction in obese or aged rats can enhance leptin sensitivity (Fernandez-Galaz et al. 2002, Peralta et al. 2002, Velkoska et al. 2003). We find that both $\mathrm{AD}$ and $\mathrm{UN}$ offspring on long-term calorie restriction appeared to be resistant to the anorexic and weight reducing effects of leptin. In both $\mathrm{AD}$ and $\mathrm{UN}$ offspring on calorie restriction, weight loss in response to leptin treatment was significantly delayed and reduced. While our observation of an apparent resistance to leptin in offspring on calorie restriction appears to be inconsistent with previous findings, it must be noted that prior studies have used much shorter periods of calorie restriction in mature rats raised on ad libitum feeding (Fernandez-Galaz et al. 2002, Peralta et al. 2002, Velkoska et al. 2003). The regime of calorie restriction used in this study represents the life-long maintenance of a reduced nutritional plane rather than a short-term dietary intervention. In the present study, leptin resistant UN offspring chronically maintained on calorie restriction are lean with little retroperitoneal fat and low plasma leptin profiles. These observations suggest that in very lean offspring there are counter-regulatory mechanisms in place that act to impede weight loss caused by leptin treatment, enabling a defence of limited adipose reserves. We observe leptin resistance in offspring on calorie restriction in the absence of hypertriglyceridemia. Banks et al. (2004) proposed that raised serum triglycerides may be responsible for leptin resistance in both obese and fasted states. However, our present finding suggests that alternative mechanisms may contribute to the development of leptin resistance in a situation of chronic calorie deficit. Calorie restriction caused a significant elevation in plasma FFA and ghrelin in both $\mathrm{AD}$ and $\mathrm{UN}$ offspring. While it is unlikely that elevated FFA levels contributed to leptin resistance per se, the potent antagonistic effects of elevated plasma ghrelin levels on leptin action could explain the leptin resistance observed in this group of animals (Shintani et al. 2001, Kim et al. 2004). We therefore speculate that antagonism of leptin through elevation of plasma ghrelin may provide an alternative mechanism to explain the development of leptin resistance in a state of chronic calorie restriction.

In the present study, we assessed leptin sensitivity by measuring the ability of leptin treatment to reduce food intake and body weight. Our data suggest that leptin resistance can evolve in three independent settings: through exposure to maternal undernutrition; from dietinduced obesity; and as a result of chronic calorie restriction. However, we find that endocrine and metabolic parameters in all offspring retain a degree of sensitivity to leptin treatment. While it seems paradoxical that offspring which appear to be leptin resistant can maintain a degree of endocrine responsiveness to leptin treatment, several recent studies suggest that leptin resistance can develop in a highly tissue specific manner (Van Heek et al. 1997, Lin et al. 2000, Munzberg et al. 2004). Our observations may relate to the development of leptin resistance within 
specific regions of the hypothalamus as demonstrated by Munzberg et al. (2004). Alternatively, these findings may represent maintenance of peripheral leptin sensitivity in the presence of central and BBB leptin resistance. Future studies are currently planned that examine central and peripheral leptin sensitivity at a molecular level in this experimental paradigm.

In conclusion, our study shows that prenatal nutrition can shape future susceptibility to obesogenic environmental influences through alterations in metabolic regulation and leptin sensitivity. We have shown that female offspring exposed to prenatal undernutrition during pregnancy develop leptin resistance in adulthood independently of postnatal diet-induced obesity. Elevations in serum triglycerides levels and hyperinsulinemia are observed in conjunction with leptin resistance in these offspring. We demonstrate that a transition from prenatal undernutrition to postnatal high fat nutrition results in accelerated weight gain, which causes rapid catch-up growth and overt obesity in UN offspring. We speculate that the pre-existing leptin resistance, in UN offspring, provides the mechanism for this increased susceptibility to diet-induced obesity. Our findings highlight a mechanism that can explain how prenatal environmental stimuli, and nutritional transition, can influence the risk of developing obesity in an obesogenic environment. Further understanding of how prenatal nutritional influences can program the endocrine control of metabolic homeostasis may provide a greater insight into the risk factors that determine susceptibility to obesogenic environmental stimuli. In addition, a deeper understanding of how prenatal and postnatal nutrition interact and influence molecular pathways involved in the development of obesity, will support the development of more effective avenues for prevention and therapeutic approaches to curb the worldwide epidemic of type-2 diabetes and obesity.

\section{Acknowledgements}

This work was supported by grants from the Health Research Council of New Zealand, the Tertiary Education Commission and the National Research Centre for Growth and Development. We thank Nikki Beckman, Rita Petal, Jennifer Miles, Alice Coveny, and Andrzej Surus for their expert technical assistance. The authors declare that there is no conflict of interest that would prejudice the impartiality of this scientific work.

\section{References}

Banks WA, Coon AB, Robinson SM, Moinuddin A, Shultz JM, Nakaoke R \& Morley JE 2004 Triglycerides induce leptin resistance at the blood-brain barrier. Diabetes 53 1253-1260.

Barker DJ 2004 The developmental origins of adult disease. Journal of the American College of Nutrition 23 588S-595S.
Brabant G, Muller G, Horn R, Anderwald C, Roden M \& Nave H 2005 Hepatic leptin signaling in obesity. FASEB Journal 19 1048-1050.

Chopra M, Galbraith S \& Darnton-Hill I 2002 A global response to a global problem: the epidemic of overnutrition. Bulletin of the World Health Organisation 80 952-958.

El-Haschimi K, Pierroz DD, Hileman SM, Bjorbaek C \& Flier JS 2000 Two defects contribute to hypothalamic leptin resistance in mice with diet-induced obesity. Journal of Clinical Investigation 105 1827-1832.

Fernandez-Galaz C, Fernandez-Agullo T, Perez C, Peralta S, Arribas C, Andres A, Carrascosa JM \& Ros M 2002 Long-term food restriction prevents ageing-associated central leptin resistance in wistar rats. Diabetologia 45 997-1003.

Frederich RC, Hamann A, Anderson S, Lollmann B, Lowell BB \& Flier JS 1995 Leptin levels reflect body lipid content in mice: evidence for diet-induced resistance to leptin action. Nature Medicine 1 1311-1314.

Gluckman PD \& Hanson MA 2004 Living with the past: evolution, development, and patterns of disease. Science 305 1733-1736.

Godfrey KM \& Barker DJ 2000 Fetal nutrition and adult disease. American Journal of Clinical Nutrition 71 1344S-1352S.

Halaas JL, Gajiwala KS, Maffei M, Cohen SL, Chait BT, Rabinowitz D, Lallone RL, Burley SK \& Friedman JM 1995 Weight-reducing effects of the plasma protein encoded by the obese gene. Science $269543-546$.

Halaas JL, Boozer C, Blair-West J, Fidahusein N, Denton DA \& Friedman JM 1997 Physiological response to long-term peripheral and central leptin infusion in lean and obese mice. PNAS 94 8878-8883.

Hales CN \& Barker DJ 2001 The thrifty phenotype hypothesis. British Medical Bulletin 60 5-20.

Harris RB, Bowen HM \& Mitchell TD 2003 Leptin resistance in mice is determined by gender and duration of exposure to high-fat diet. Physiological Behaviour 78 543-555.

Heshka JT \& Jones PJ 2001 A role for dietary fat in leptin receptor, OB-Rb, function. Life Science 69 987-1003.

Heymsfield SB, Greenberg AS, Fujioka K, Dixon RM, Kushner R, Hunt T, Lubina JA, Patane J, Self B, Hunt P et al. 1999 Recombinant leptin for weight loss in obese and lean adults: a randomized, controlled, dose-escalation trial. Journal of the American Medical Association 282 1568-1575.

Kim MS, Namkoong C, Kim HS, Jang PG, Kim Pak YM, Katakami H, Park JY \& Lee KU 2004 Chronic central administration of ghrelin reverses the effects of leptin. International Journal of Obesity Related Metabolic Disorders 28 1264-1271.

Klein S, Coppack SW, Mohamed-Ali V \& Landt M 1996 Adipose tissue leptin production and plasma leptin kinetics in humans. Diabetes 45 984-987.

Lee GH, Proenca R, Montez JM, Carroll KM, Darvishzadeh JG, Lee JI \& Friedman JM 1996 Abnormal splicing of the leptin receptor in diabetic mice. Nature 379 632-635.

Levin BE, Dunn-Meynell AA \& Banks WA 2004 Obesity-prone rats have normal blood-brain barrier transport but defective central leptin signaling before obesity onset. American Journal of Physiology, Regulatory, Integrative and Comparative Physiology 286 R143-R150.

Lin L, Martin R, Schaffhauser AO \& York DA 2001 Acute changes in the response to peripheral leptin with alteration in the diet composition. American Journal of Physiology, Regulatory, Integrative and Comparative Physiology 280 R504-R509.

Lin S, Thomas TC, Storlien LH \& Huang XF 2000 Development of high fat diet-induced obesity and leptin resistance in C57Bl/6J mice. International Journal of Obesity Related Metabolic Disorders 24 639-646.

Lollmann B, Gruninger S, Stricker-Krongrad A \& Chiesi M 1997 Detection and quantification of the leptin receptor splice variants $\mathrm{Ob}-\mathrm{Ra}, \mathrm{b}$, and, e in different mouse tissues. Biochemical and Biophysical Research Communications 238 648-652. 
Maffei M, Halaas J, Ravussin E, Pratley RE, Lee GH, Zhang Y, Fei H, Kim S, Lallone R, Ranganathan S et al. 1995 Leptin levels in human and rodent: measurement of plasma leptin and ob RNA in obese and weight-reduced subjects. Nature Medicine 1 1155-1161.

Martorell R, Stein AD \& Schroeder DG 2001 Early nutrition and later adiposity. Journal of Nutrition 131874 S-880S.

McMillen IC \& Robinson JS 2005 Developmental origins of the metabolic syndrome: prediction, plasticity, and programming. Physiological Reviews 85 571-633.

Montague CT, Farooqi IS, Whitehead JP, Soos MA, Rau H, Wareham NJ, Sewter CP, Digby JE, Mohammed SN, Hurst JA et al. 1997 Congenital leptin deficiency is associated with severe early-onset obesity in humans. Nature 387 903-908.

Monteiro CA, Moura EC, Conde WL \& Popkin BM 2004 Socioeconomic status and obesity in adult populations of developing countries: a review. Bulletin of the World Health Organisation 82 940-946.

Munzberg H, Flier JS \& Bjorbaek C 2004 Region-specific leptin resistance within the hypothalamus of diet-induced obese mice. Endocrinology 145 4880-4889.

Ozanne SE 2001 Metabolic programming in animals. British Medical Bulletin 60 143-152.

Pelleymounter MA, Cullen MJ, Baker MB, Hecht R, Winters D, Boone T \& Collins F 1995 Effects of the obese gene product on body weight regulation in ob/ob mice. Science $269540-543$.

Peralta S, Carrascosa JM, Gallardo N, Ros M \& Arribas C 2002 Ageing increases SOCS-3 expression in rat hypothalamus: effects of food restriction. Biochemical and Biophysical Research Communicaitons $296425-428$.

Popkin BM \& Gordon-Larsen P 2004 The nutrition transition: worldwide obesity dynamics and their determinants. International Journal of Obesity Related Metabolic Disorders 28 (Suppl 3) S2-S9.

Rodgers A, Vaughan P, Prentice T, Tan-Torres Edejer T, Evans D \& Lowe J 2002 The World Health Report 2002: Reducing Risks, Promoting Healthy Life. Geneva, Switzerland: World Health Organization.

Schwartz MW, Seeley RJ, Campfield LA, Burn P \& Baskin DG 1996 Identification of targets of leptin action in rat hypothalamus. Journal of Clinical Investigation 98 1101-1106.

Shimabukuro M, Koyama K, Chen G, Wang MY, Trieu F, Lee Y, Newgard CB \& Unger RH 1997 Direct antidiabetic effect of leptin through triglyceride depletion of tissues. PNAS 94 4637-4641.
Shintani M, Ogawa Y, Ebihara K, Aizawa-Abe M, Miyanaga F Takaya K, Hayashi T, Inoue G, Hosoda K, Kojima M et al. 2001 Ghrelin, an endogenous growth hormone secretagogue, is a novel orexigenic peptide that antagonizes leptin action through the activation of hypothalamic neuropeptide $\mathrm{Y} / \mathrm{Y} 1$ receptor pathway. Diabetes 50 227-232.

Van Heek M, Compton DS, France CF, Tedesco RP, Fawzi AB, Graziano MP, Sybertz EJ, Strader CD \& Davis HR, Jr. 1997 Diet-induced obese mice develop peripheral, but not central, resistance to leptin. Journal of Clinical Investigation 99 385-390.

Velkoska E, Morris MJ, Burns P \& Weisinger RS 2003 Leptin reduces food intake but does not alter weight regain following food deprivation in the rat. International Journal of Obesity Related Metabolic Disorders 27 48-54.

Vickers MH, Breier BH, Cutfield WS, Hofman PL \& Gluckman PD 2000 Fetal origins of hyperphagia, obesity, and hypertension and postnatal amplification by hypercaloric nutrition. American Journal of Physiology and Endocrinological Metabolism 279 E83-E87.

Vickers MH, Ikenasio BA \& Breier BH 2001 IGF-I treatment reduces hyperphagia, obesity, and hypertension in metabolic disorders induced by fetal programming. Endocrinology 142 3964-3973.

Vickers MH, Ikenasio BA \& Breier BH 2002 Adult growth hormone treatment reduces hypertension and obesity induced by an adverse prenatal environment. Journal of Endocrinology 175 615-623.

Vickers MH, Gluckman PD, Coveny AH, Hofman PL, Cutfield WS, Gertler A, Breier BH \& Harris M 2005 Neonatal leptin treatment reverses developmental programming. Endocrinology 146 4211-4216.

Zammit VA 2002 Insulin stimulation of hepatic triacylglycerol secretion in the insulin-replete state: implications for the etiology of peripheral insulin resistance. Annals of the New York Academy of Science $96752-65$.

Zammit VA, Lankester DJ, Brown AM \& Park BS 1999 Insulin stimulates triacylglycerol secretion by perfused livers from fed rats but inhibits it in livers from fasted or insulin-deficient rats implications for the relationship between hyperinsulinaemia and hypertriglyceridaemia. European Journal of Biochemistry 263 859-864.

Received in final form 7 February 2006

Accepted 8 February 2006

Made available online as an Accepted Preprint 13 February 2006 